\title{
The Business Ecosystem of the Chinese Software Industry ${ }^{*}$
}

\author{
Jiangping Wan ${ }^{1,2}$, Hui Zhang ${ }^{1}$, Xiaoyao Wan ${ }^{1}$, Weiping Luo ${ }^{1}$ \\ ${ }^{1}$ School of Business Administration, South China University of Technology, Guangzhou, China; \\ ${ }^{2}$ Institute of Emerging Industrialization Development, South China University of Technology, Guangzhou, China. \\ Email: scutwjp@126.com; shidelan@163.com; 294663012@qq.com; luoweiping18@139.com
}

Receive December 28 ${ }^{\text {th }}$, 2010; revised February 26 ${ }^{\text {th }}$, 2011; accepted March 25 ${ }^{\text {th }}, 2011$.

\begin{abstract}
The software industry business ecosystem is proposed, and a business ecosystem health evaluation model is built. Its factors are in the following: stability factors, including productivity, diversity and resilience; the sustainability factors, including productivity, vitality and creativity. And this evaluation model is applied to the Chinese software industry business ecosystem health analysis. Finally, some considerations on the industrial policy and the industrial clusters are put forward.
\end{abstract}

Keywords: Software Industry, Business Ecosystem, Health Research, Stability, Sustainability, Industrial Policy, Industrial Cluster

\section{Introduction}

The business ecosystem is a new concept [1] proposed by American strategy expert James F. Moore with the ecology viewpoint regarding modern enterprise competition issues. He pointed out that the business ecosystem is an economical unified body which is composed of the individual, the organization and the subsystem, taking the interaction of organizations and individual as the foundation. Among them, the individual refers to consumer individual, the organizations refer to all types of enterprises, the subsystem refers to the strategic alliance between the companies. Marco Iansiti and Ray Levien believed that all enterprises and the supplier, the distributor, the outsourcing service company, the financing organization, the key technologies provider, the supplementary product manufacturer, the competitor, the customer, the supervision organization, the media and the related government apparatus etc. are the business ecosystem's species. Business environment is a close-knit, mutually dependent symbiotic system [2].

\section{Software Industry Business Ecosystem}

According to the literature [1] and [2], the software industry business ecosystem (Figure 1) is put forward. Its

*This research was supported by Key Project of Guangdong Province Education Office (06JDXM63002), and QualiPSo (IST-FP6-IP-0347 63) main activities include various types of economic individuals and organizations: the upstream supplier, software developers, service providers and channel vendors, consumers, competitors and other related industries and businesses, government agencies, industry and community organizations etc.. They form a whole with mutual competition and cooperation, common development and evolution, and a specific function in the economy. In the software industry ecosystem, around the software value chain (suppliers, the core product developers, service providers, marketing channels) system constitute the core business circle; The upstream supplier and the core product's customer etc. form the outer-level Business circle of the system; While the financial chain (venture capital fund, investor, bank etc.) and the policy chain (standard-setting government and other Quasi-governmental organization, trade association, standard-setting organization etc.) as well as the competitors form the outermost-level circle ecological environment of the system. For example, US's Silicon Valley is a typical software industry business ecosystem [3].

\section{Business Ecosystem Healthy Evaluation Model}

Marco Iansiti and Ray Levien proposed three important healthy business ecosystem assessment criteria [2]. 1) Productivity. That is, whether a commercial network will 


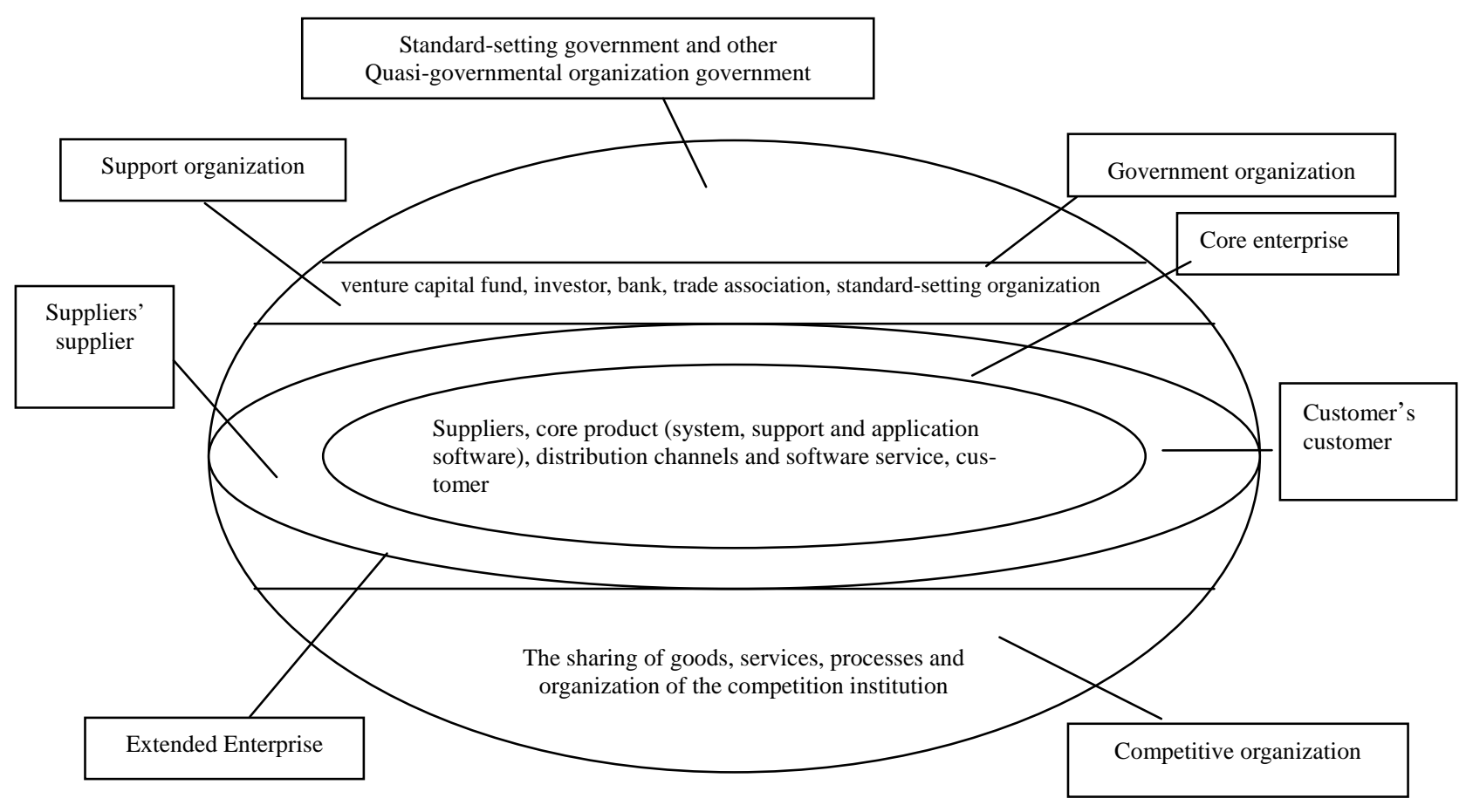

Figure 1. Software industry business ecosystem.

be able to continually transform the technology and other innovative raw materials into a lower cost and on investment. 2) Robustness. Namely the system resists each kind of disturbance and destruction ability, generally weighed by the member's survival rate in the system. 3) Slit space creation ability (niche creation). Namely system whether to have the multiplicity, whether to have ability to create the more segmentation markets unceasingly, creates the valuable new function, generally measured by the application degree of innovation.

We argues that a healthy business ecosystem must have two basic characteristics: First, the stability of that business ecosystems have a well-developed internal defense mechanisms to resist the rapid changes in the external environment; Second, the sustainability of that system keep digging its own inherent potential to achieve sustainable development. Therefore, this article attempts to construct an evaluation model [4]: the stability of one of the factor, including productivity, diversity, resilience etc.; sustainability factor, including productivity, vitality, creativity etc.

Stability factors: 1) Productivity: the energy is bigger that explains various living things survive in a good shape in the ecosystem, but the productive forces is only the healthy ecosystem's necessary condition, it is not that the ecosystem has higher energy is healthier. It can use the productivity to weigh. 2) Diversity: intricate food web of the ecosystem is an important condition to maintain a relative stabilization, the more complex food web, the bigger the ecosystem's ability to resist outside interference, and it dose not lead to the collapse of the entire ecosystems as a result of a link in the chain fell off. According to industry interior product mix and business models it could do qualitative analysis. 3) Resilience: it refers to the system ability to gradually recovery the capacity of ecosystem in the disappearance of the external.

It may carry on the qualitative analysis according to the changes around situation.

Sustainability factors: 4) Productivity: That Transforms the new technology into the product at the least cost is just the productivity in the business ecosystem. Therefore, the level of productivity means the size of ecosystem's ability. If creation ability is low, each member's livelihood value will atrophy in the business ecosystem, it will lead to over-exploit the balance to the imbalance and creation value pressure. That is a dynamic process from the ecosystem. The ecosystem will be more and more unhealthy, finally it will move toward ultimate demise. It may use the investment return rate to weigh. 5) Vitality: It is essential to the system's sustainable development. System's vitality and each interior species' vitality in the system are closely linked, it may use the system survival rate to weigh. 6) Market creativity: In the market that the dispersive species enables the ecosystem to have the multiplicity. It is be beneficial to absorb the negative impact of the changing environment. Multiplicity is more advantageous to the display creativity, thus generates the value. then to the balance. In the 
process, the system has completed an external impact response through own adjustment.

\section{Chinese Software Industry Business Eco- system Analysis}

This article has made an analysis according to the above evaluation model for the Chinese software industry business ecosystem (time 1999-2005).

1) Productivity. Figure 2's left side of 7 pair of data is the software product, its right side is the software service, and the total length is the software industry total output value. We can see that from 1999 to 2005, during seven years, the total industrial value developed rapidly, in 2005, the total output value achieved nearly 10 times of 1999 industrial value.

2) Diversity. The Ministry of Information Industry in 2003 implemented the software research and development and production enterprise statistical survey, in nationwide scale, according to sums of "the software product revenue”, "the system integration revenue” and "the software service revenue", among the selected Top 100 in software industry, Huawei, ZTE, Hisense Group, had the honor to receive first three, Haier Group and Digital China (China) come after (Figure 3). Figure 3 indicated that China's software industry interior has a complex industry chain (net), and the business relation intensively contacting upstream and downstream enterprise. This article holds that China's software industry ecosystem is basically healthy. But it is noteworthy that all the domestic big software closely connected with foreign capital large-scale IT enterprise. There are few relations between them and China's other small scale software enterprises, even between these five major enterprises' direct relations are also very few, while they connect with each other through other company's intermediate products.
3) Resilience. Through the investigation we discovered that Chinese software industry can be divided into two major categories: the software product and the software serves. While the software product can be divided into three broad categories: system software, application software and support software. This article calculates the occupied proportion of the three types of software products, according to the classification data of software product (Figure 4). Figure 4 indicated that 2001 was an inflection point. The system was at the stable state of equilibrium before 2001. After 2001, as a result of user's needs' change, the system software, support software occupied proportion reduced, but the application software occupied proportion increased sharply.

4) Productivity. This article replaces with the rate of sales profit. Figure 5 demonstrated that in 2001 under the influence which the overseas software industry recession, Chinese software industry also had a big recession. But from 2002 to 2005, the rate of return on investment was in the rise process. That is to say that Chinese software industry is easy to be influenced by the external shocks, but itself has the continuing development power.

5) Vitality. According to the survival rate data the registered number of software vendors as well as the number of products, from 1999 to 2005, it was discovered in the software industry, the number software vendors and the software products output were in proceeding steadily, there was no significant change (Table 1). This article holds that the survival of the system is in good condition.

6) Creativity. The data (http://www.21our. com) demonstrated that the most cross-enterprise's software research and development funds accounted for the turnover above 10\%, Microsoft even achieved about 20\%. But Chinese Software Enterprise's research and development

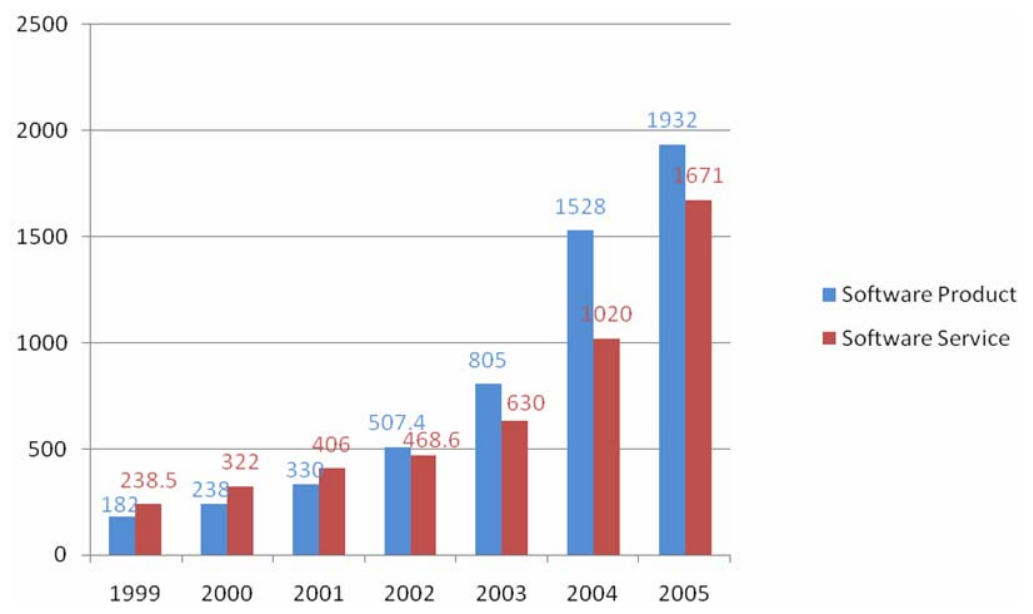

Figure 2. Chinese software industry productivity source: Chinese Electronic Information Industry Yearbook $2001 \sim 2006$ [5]. 


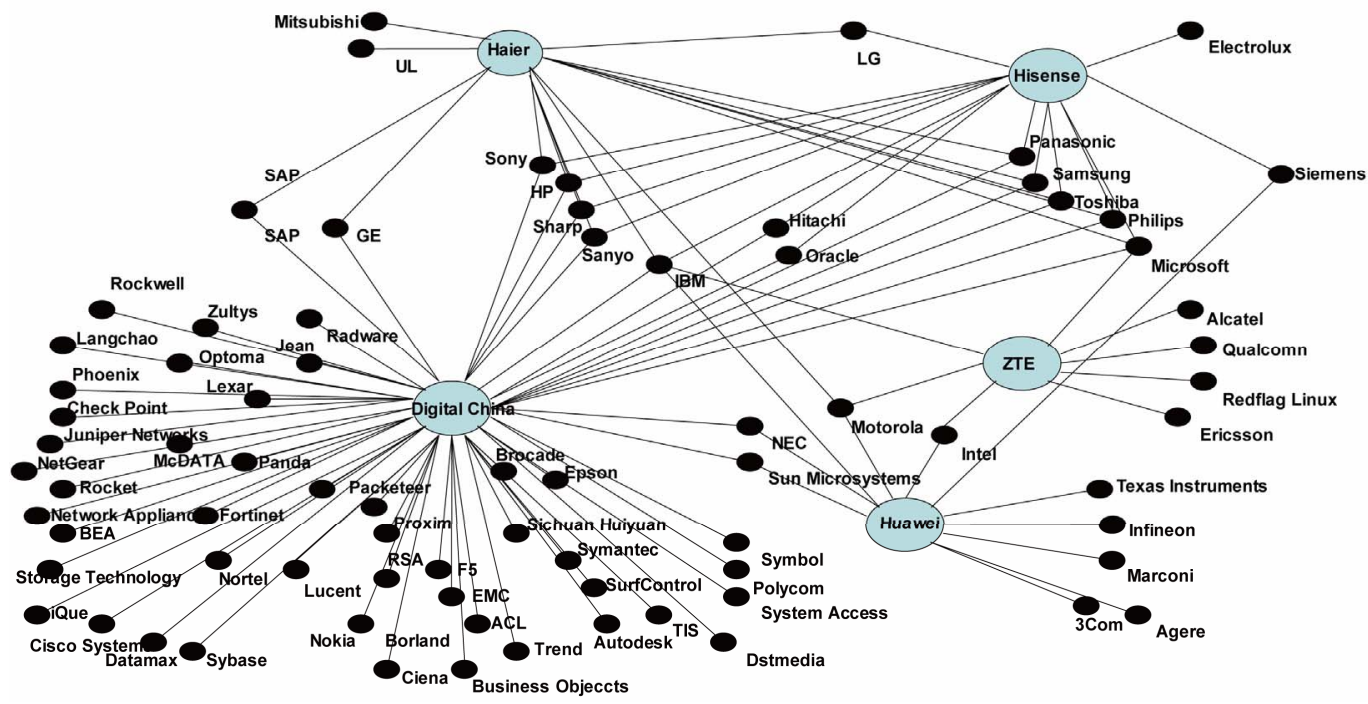

Figure 3. Inner structure of Chinese software industry source: sectoral system of innovation in China-the case of software sector [6].

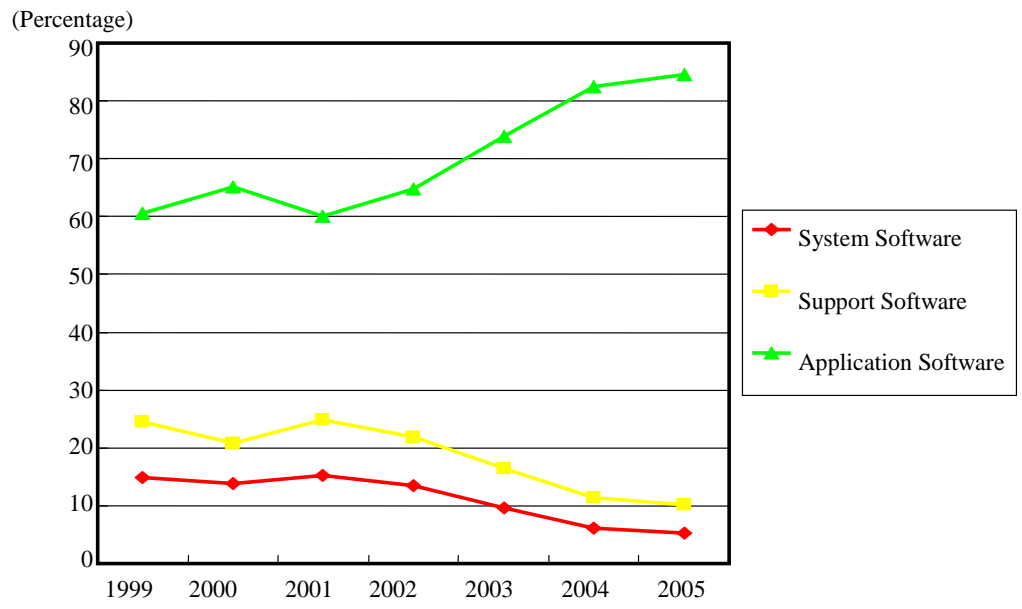

Figure 4. The percentage of various products of Chinese software industry Source: Chinese Electronic Information Industry Yearbook 2001 2006 [5].

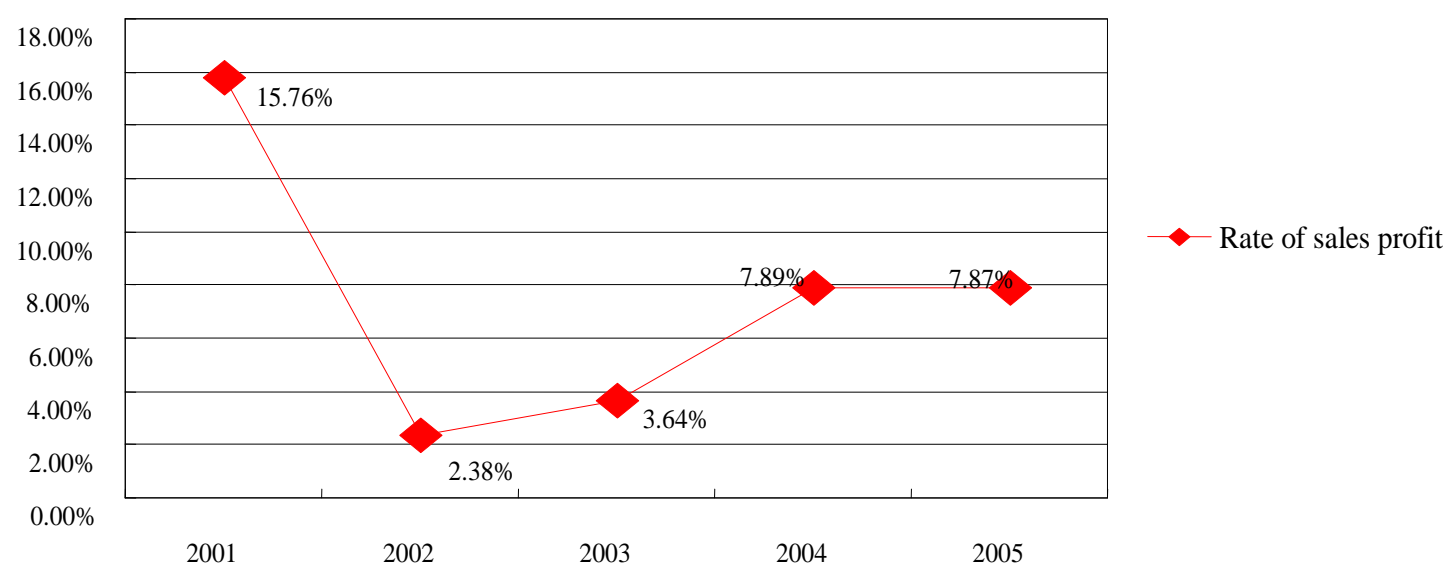

Figure 5. The rate of sales profit in Chinese software industry from 2001 to 2005 Source: Chinese IT industry map [7]. 
Table 1. The number of enterprises in china's software industry and the amount of products.

\begin{tabular}{ccc}
\hline Years & $\begin{array}{c}\text { The number of software } \\
\text { enterprises }\end{array}$ & $\begin{array}{c}\text { The amount of } \\
\text { software products }\end{array}$ \\
\hline 2001 & 2736 & 10900 \\
2002 & 6282 & 18900 \\
2003 & 8700 & 23450 \\
2004 & 10700 & 28401 \\
2005 & 12458 & \\
\hline
\end{tabular}

Data resources: Yearbook of china's electronic information industry $2001 \sim$ 2006 [6].

investment proportion was widely low, therefore Chinese Software Enterprise's technological innovations basically were in primary and low-end market. At the same time, the replacement of software products is very quick, while transforming the technological innovation into the product is difficult. Because the domestic enterprise does not have the brand and the customer superiority in the system software, the market segment basically was subdivided by the Foreign-funded enterprise.

The application software and the middleware product due to the localized application characteristic and the reason that the development time was not long, the domestic enterprise had not been widened differences by the foreign enterprise at present. This is the so-called niche market, for example UFIDA and KINGDEE financial management software grasped the accurate market position, this software needs of society was still strong in 2007, the market sales volume amounted to 1,390,000,000 Yuan, grew $13.1 \%$ compared to 2006, had seized $13.0 \%$ of the general application software market (http://industry. ccidnet.com).

\section{Discussions and Suggestions}

Statistical data shows that software industry output value had a large scale growth in recent years. Simultaneously the development of Chinese software industry, regardless of the technical force, the fund strength or the profession experience had a certain accumulation, which has laid a solid foundation for the future development. At the same time, Chinese software industry lacks the software core product and the key technologies, also lacks the software core enterprise. China software industry has the problem and difficulty in the globalization of market. The superiority population has the control influence to the entire community, because in the face of external interference the diversity it supports has acted as buffer function, thus it has defended system's stability. Therefore, Chinese software industry is the appearance of healthy ecosystem but has the hidden trouble. It is in a sub-healthy state which has the development foundation and power but stability insufficient. The key lies in grasps the market position, establishes own core competence. The construction of healthy software industry business ecosystem (system's stability and sustainable development) not only needs each economic entity to consummate their functions, but also needs to strengthen their coordination and cooperation.

Industrial policy. 1) We must strengthen the government function, establish the good policy environment. First, we must strengthen the government market supervision, social management and public service aspects' responsibility, consummate a legal system and formulate the preferential benefit reasonable policy to guide the industry healthy development. In software industry's policies and regulations, we should particularly pay attention to the protection of intellectual property rights, We must strengthen each kind of intellectual property protection policies and implementation force, enlarge the strike force of software piracy and pirate phenomenon, enhance the propaganda of the software intellectual property protection knowledge and keep the consciousness of national intellectual property protection. It is beneficial to protect core technologies, promote innovation as well as the establishment of public environment. Secondly, the government support object must be clear. The software industry develops rapidly, the unceasing innovation and the unceasing fusion make the industrial chain full of fleeting market opportunities. Which opportunities can bring about the invention, which inventions can rise to the standard altitude and which standards can be promoted have the significant influence to the Chinese software industry development. Therefore, it must be strengthen the software industry technology foresight, here "the technology", is not the pure technology of traditional narrow understanding, but is "the big science and technology" in the significance technology which closely associates with the science, the economy, the society, politics, the environment etc.; Here "foresight”, also is not the pure forecast future, but is emphasis on the meaning that contains "rational choose the future and take the initiative to shape the future" $[8,9]$.

2) We should establish a good software industry investment environment. Including we encourage and guide the social capital to go to the software industry, positively attract the foreign capital, establish venture capital fund which is suitable for the software industry development and create all convenient conditions for the venture capital fund's lawful operation.

3) We should display the market resources' superiority, promote Chinese software Industrialization development. The modern service industry's development brings the strategic opportunities for our country software industry. Modern service industry simultaneously has technology, 
capital, labor-intensive features. It both has the very bright region characteristic, and has the very bright cultural characteristic. Developing modern service industry in China, like the software industry, may transform the population resources superiority to the numerous competitive advantages, break the resources and the environment restriction effectively. Prof. Z. W. Xu argued that 2006-2020 computer industry will have five big transition [9]: a) the magnitude transition, its goal is in odder to enhance several magnitudes computer's performance index; b) the efficiency transition, its goal is in odder to raise computer's efficiency doubled and re-doubled; c) the market demand transition, the computer market enters universal stage, the subject of computer science is application; d) Technology impetus transition, forced by three big technical impetuses: the computer electronics, sensor networks and grid calculates; e) Vitality. According the survival rate data from 1999 the registered number of software vendors as well as a number of products to 2005 it was discovered in the software industry, regardless of the number software vendors or the software products output were in proceeding steadily, there was no significant change (Table 1).

Industrial cluster. 1) We should construct the National Software Park. Our country had already built 11 national-level software park. Therefore it is important to give full play the link and the platform function of the national software park, guide to form the software industry system and a good industrial chain, which integrate the collection research and development, the production, the service and the application as a body, rapidly form the scale advantage, the cost advantage and the technical advantage, build the overall brand image. It is crucial for Chinese software's industry long-term steady development to form the international competitiveness innovation clusters of software industry that take the software leading enterprise as the center, the big and medium and small enterprise collaborate, unify produce, study and research.

2) Improve the software industry chain. In the healthy industrial chain enterprises form a reasonable division of chain, each enterprise has its own dedicated domain in the division of chain, on the one hand it may make enterprise's specialized direction more special, then raises the level, forms the scale, saves the cost, raises the efficiency, enhances enterprises' core competitiveness; On the other hand it draws support from the market mechanism through the industrial chain's integration and assignment function, expands the industry scale fast, then promotes the industry overall competitive power. However Chinese software specialization's division of labor has not formed. Each link of the industrial chain didn't join very well, the whole is in the global value chain's low end. So, first, it should expand the research and development investment, break through the software core technologies, and improve the technological innovation ability. Implement central and large investment to the software core technologies' research and development. Set up a special fund by the country to focus support the technology located at the middle and upper reaches in software industry chain, mainly including basic and common software such as operating system, large-scale data management system, development platform, information security, large-scale application software systems, component library etc.. The second is to strengthen the alliance or merger with the core of industrial chain integration, strive for the development in the competition. Prof. D. H. Ju argued that a mature software industry should contain a mature enterprise construction, a mature product line, a mature human resources team, a mature technology development system as well as a mature support environment [10].

\section{Conclusions}

This article proposed the software industry business ecosystem with the business ecosystem, and tried to build the business ecosystem healthy evaluation model, and applied this evaluation model to carry on the healthy analysis of the Chinese software industry business ecosystem. This evaluation model also needs the further research and the practice. We hope it can throw a sprat to catch a herring, play some effective inspiration for Chinese software industry business ecosystem's healthy development.

\section{Acknowledgements}

Thank for helpful discussion with, Mr. Zhu Shiqing, Mrs. Xiong Ruiping, Mrs Huang Huajie.

\section{REFERENCES}

[1] J. F. Moore, J. Liang and F. X. Yang Translated, "Decline and Fall of the Competition: Strategy and the Leadership of Business Ecosystem Times,” Beijing Press, Beijing, 1999, pp. 17-20.

[2] M. Iansiti and G. L. Richards, "Information Technology Ecosystem Health and Performance,” 2006. http://hbswk. hbs.edu/item/ 5405.html

[3] J. P. Wan, Y. F. Wang and W. Zou, "Develop Knowledge-Intensive Service Industries, Promote the Development of Eco-Business Network-The Development of the Software Industry in Guangdong as an Example," Science and Technology Management, Vol. 27, No. 7, 2007, pp. 44-45.

[4] D. J. Rapport, C. L. Gaudet, R. Constanza, P. R. Epstein and R. Levins, "Ecosystem Health: Principles and Practice,” Wiley-Blackwell, Boston, 1998, pp. 19-23.

[5] “Chinese Electronic Information Industry Yearbook," 
The Publishing House of Electronics Industry, Beijing, 2001-2006.

[6] Q. Wu and K. Miyazaki, "Sectoral System of Innovation in China-The Case of Software Sector," International Journal of Knowledge and Systems Sciences, Vol. 2, No. 3, 2006, pp. 52-60.

[7] Chinese Industrial Map Editorial Board, "Map of Chinese IT Industry 2006-2007,” Monitor Center of Chinese Economic Boom, Social Sciences Documentation Publishing
House, Beijing, 2006, p. 12.

[8] J. B. Wan, "Technology Foresight: Science and Technology Strategy-Planning and Science and Technology Policy-Making,” Chinese Soft Science, No. 5, 2002, pp. 62-66.

[9] Z. W. Xu, "Computer Enlightenment the Future of Computer,” Tsinghua University Press, Beijing, 2006, p. 10.

[10] D. H. Ju, “To Build a Mature Software Industry,” 2001. http:// www.iturls.com/Articles/Articles_4.asp,2001. 